\title{
Trajectories of Self-efficacy and Achievement Goals: A Developmental Approach
}

\author{
Huy P. Phan ${ }^{1}$ \\ ${ }^{1}$ School of Education, The University of New England, Armidale, Australia \\ Correspondence: Huy P. Phan, School of Education, The University of New England, Armidale NSW, 2351, \\ Australia. Tel: 61-2-6773-3327. E-mail: hphan2@une.edu.au
}

Received: April 24, 2012

Accepted: June 29, 2012

Online Published: August 3, 2012

doi:10.5539/jedp.v2n2p110

URL: http://dx.doi.org/10.5539/jedp.v2n2p110

\begin{abstract}
An emerging interest in cognition and motivation has recently involved the study of rate of change of self-efficacy and achievement goals. We used latent growth modeling (LGM) to test a structural equation model that involved prior academic grades, self-efficacy, mastery and performance-approach goals, and academic achievement measured over a two-year period. A sample of 228 (106 females, 122 males) of second-year students enrolled in mathematic participated in this study. Multivariate growth curve analyses indicated statistically significant effects of prior academic achievement on the intercept factors of the three mentioned constructs; prior academic achievement also exerted a negative effect on the slope factor of mastery goals, and a positive effect on mathematic achievement. Examination of the three trajectories showed increases in change in all three constructs. Evidence ascertained from this research investigation is informative in instructional policies and applied teaching practices.
\end{abstract}

Keywords: self-efficacy, achievement goal orientation, developmental approach, growth modelling

\section{Introduction}

In the area of cognition and motivation, research has shown that personal self-efficacy (Bandura, 1986, 1997) and achievement goal orientations (Ames \& Archer, 1988; Archer, 1994; Elliott \& Dweck, 1988; Harackiewicz, Barron, Pintrich, Elliot, \& Trash, 2002; Pintrich, Conley, \& Kempler, 2003) contribute to the predictions of learning in achievement contexts. One important progress that has been advanced recently involves examinations of rate of change of cognitive and motivational outcomes (e.g., Caprara et al., 2008; Phan, 2011b, 2012). The methodological use of growth modeling procedures (Bollen \& Curran, 2006; Duncan, Duncan, Strycker, Li, \& Alpert, 1999; Hancock \& Lawrence, 2006; McArdle \& Nesselroade, 2003), in particular, has enabled researchers to test and identify various developmental courses of internal cognitive and non-cognitive processes of academic learning. Consequently, as an extension to the mentioned inquiry, we decided to explore second-year university students enrolled in mathematic over a period of two years.

\subsection{Theoretical Frameworks: An Amalgamation for Examination}

The conceptual model we tested in this study, as shown in Figure 1, is an amalgamation of two major theoretical frameworks: personal self-efficacy and achievement goals. Personal self-efficacy, central to Bandura's (1986, 1997) social cognitive theory, deals primarily with one's perceived sense of competence to execute required courses of actions. Self-efficacy governs one's choice of behaviors and aspirations, and the mobilization and maintenance of effort. Self-efficacy beliefs help determine how much effort individuals will expend on an activity, how long they will persevere when confronting obstacles, and how resilient they will be in the face of adverse situations. In general, self-efficacy has been reported to play a potent role in human agency in both academic and non-academic settings (Pajares, 1996b; Schunk, 1991, 1995).

The achievement goals framework, similar to personal efficacy (Bandura, 1986, 1997), has received considerable attention in educational psychology. Over the past three decades, research development has resulted in different theoretical models of achievement goals: (i) the dichotomous model (Dweck \& Leggett, 1988) indicating the categorization of mastery and performance goals; (ii) the trichotomous model (Elliot, 1999; Elliot \& Church, 1997; Elliot \& Harackiewicz, 1996; Harackiewicz, Barron, Pintrich, et al., 2002) categorizes performance goals into performance-approach and performance-avoidance goals; (iii) the $2 \times 2$ model (Elliot \& McGregor, 2001; 
Elliot \& Murayama, 2008) involves the categorization of both mastery and performance goals into the distinction of approach versus avoidance (e.g., mastery-approach vs. mastery-avoidance); and (iv) the multiple-goals model (Harackiewicz, Barron \& Elliot, 1998; Harackiewicz, Barron, Pintrich, et al., 2002; Pintrich, 2000; Valle et al., 2003). In conjunction with other achievement goals perspectives (e.g., $2 \times 2$ ), the multiple-goals perspective suggests that, in general, individuals may orientate and adopt different goals in their learning, namely mastery, performance-approach and performance-avoidance, and work-avoidance (Elliot, 1999; Elliot \& Church, 1997; Harackiewicz, Barron, Carter, Letho, \& Elliot, 1997; Harackiewicz, Barron, Pintrich, et al., 2002). The evolution of these theoretical models arises from a need to explain individuals' differing patterns of cognition, motivation, and behavior.

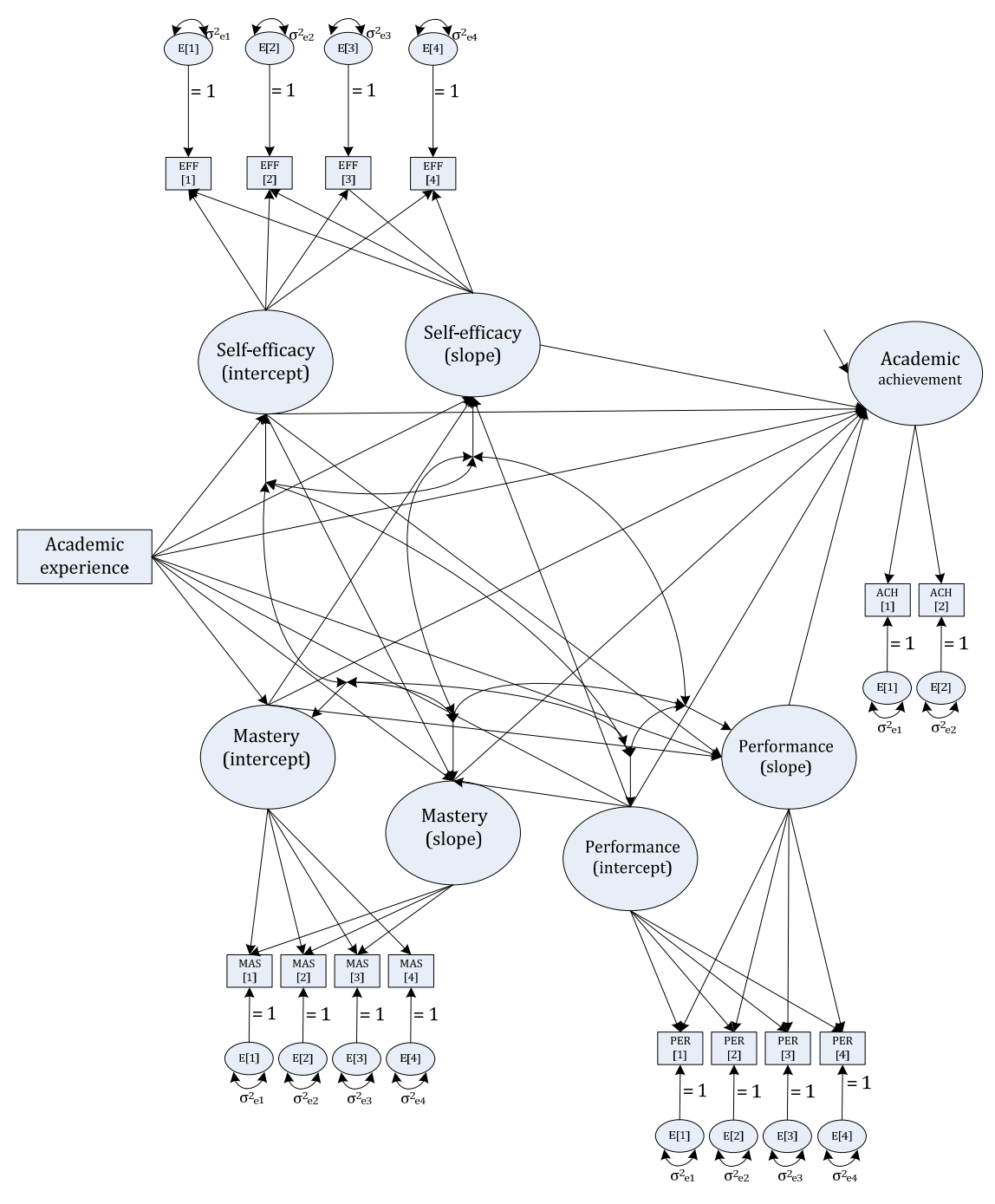

Figure 1. A multivariate growth curve model: prior academic grades, self-efficacy, achievement goals and academic achievement

Research that has been conducted to date suggests each goal type has distinctive characteristics and associates differently to various cognitive and motivational processes involved in learning. Notwithstanding the limitations that exist, the trichotomous framework and the inclusion of work-avoidance goals (Harackiewicz et al., 1997; Meece, Blumenfeld, \& Hoyle, 1988) has been studied extensively in different educational contexts and levels (e.g., Church, Elliot, \& Gable, 2001; Elliot, McGregor, \& Gable, 1999; Harackiewicz, Barron, Tauer, \& Elliot, 2002; Senko \& Miles, 2008; Simons, Dewitte, \& Lens, 2004).

Quantitatively, within the framework of structural equation modeling (SEM), research has yielded some relatively inconclusive evidence for mastery and performance-approach goal orientations. Some research studies have, for example, reported a positive association between a mastery goal orientation and academic achievement 
(Phan, 2010b; e.g., Tanaka \& Yamauchi, 2001; e.g., Vansteenkiste, Simons, Lens, Soenens, \& Matos, 2004), whereas others indicated a null relationship (e.g., Dupeyrat \& Mariné, 2005; Fenollar, Román, \& Cuestas, 2007; Liem, Lau, \& Nie, 2008; Senko \& Miles, 2008; Sins, van Joolingen, Savelsbergh, \& van Hout-Wolters, 2008).

A similar pattern in findings has also been ascertained for the role of a performance-approach goal orientation, wherein some studies have indicated a positive effect on students' academic achievements (e.g., Church et al., 2001; Durik, Lovejoy, \& Johnson, 2009; Harackiewicz, Barron, Tauer, et al., 2002; Phan, 2010a; Senko \& Miles, 2008), and others reported a null association betweem the two constructs (Dupeyrat \& Mariné, 2005; Fenollar et al., 2007; Liem et al., 2008). Consequently, given the inconclusiveness of the relations between mastery and performance-approach goal orientations and academic achievement, it is prudent for us to explore and clarify this theoretical positioning. Furthermore the exclusive study of the trichotomous model (Elliot, 1999; Elliot \& Church, 1997; Elliot \& Harackiewicz, 1996; Harackiewicz, Barron, Pintrich, et al., 2002), in particular, the mastery and performance-approach goal orientations, has implications for instructional policies and applied teaching practices. There is research that has explored, for example, the specific contributions of both achievement goal types in totality (Phan, 2009a, 2009b). This focus is prudent, given that both mastery and performance-approach goals may positively enhance students' learning in motivational contexts.

Our conceptual model, different from those tested in previous longitudinal and cross-sectional studies for self-efficacy (Bong, 2002; e.g., Pajares \& Kranzler, 1995; e.g., Pajares \& Miller, 1994; Skaalvik \& Rankin, 1998) and achievement goals (e.g., Fenollar et al., 2007; Harackiewicz, Barron, Tauer, Carter, \& Elliot, 2000; Harackiewicz, Barron, Tauer, et al., 2002; Liem et al., 2008) signifies three major characteristics:

1) The initial states and rate of change of self-efficacy and mastery and performance-approach goals and their possible influences on academic achievement in mathematic.

2) The role of prior academic grades as an antecedent of self-efficacy and mastery and performance-approach goals.

3) The six time points of data collection and transitional period between Time $1\left(T_{1}\right)$ and Time $2\left(T_{2}\right)$. We contend that our investigation may provide theoretical and methodological contributions towards the study of trajectories and how students' self-efficacy beliefs and achievement goal orientations vary over time.

\subsection{Trajectories of Self-efficacy and Achievement Goals}

Our proposition entails a paradigm shift in research development, exploring short-term trajectories of students' mastery and performance-approach goal orientations as they transition from one academic year to the next. This emphasis enables us to consider and address some questions, for example: is there an increase in a mastery goal orientation, and likewise a decrease for a performance-approach goal, over the course of one's learning?

We propose a similar conceptualized positioning for personal self-efficacy, and query the states of stability/instability of this self-belief construct in university learning. There is empirical evidence to suggest that self-efficacy beliefs for academic learning change continuously as students progress and transition from one year to another (e.g., Caprara et al., 2008; Phan, 2011c). Some researchers have contended that over the course of the secondary school and university years, students experience a myriad of emotional, physical, and psychosocial attributes. Peer pressure and the need to identify and affiliate socially with others, for example, may influence and shape students' academic self-efficacy beliefs (Britner \& Pajares, 2006; Caprara et al., 2008; Harter, 1996). Some students may prefer and spend unspecified amounts of time, attention, and effort expenditure on non-academic and/or extracurricular activities. Lowered interests and priorities in academia and learning may consequently result in students experiencing difficulties and/or lethargic behaviors, thereby negating a heightened sense of self-efficacy.

In essence, there is credence to suggest that various extraneous factors from environmental settings (e.g., peer pressure) may contribute to the shaping of students' self-efficacy beliefs for academic learning. Our research examination, although acknowledging the importance of external contributions, is more concerned with the identification of developmental courses of self-efficacy beliefs and achievement goal orientations. This focus may illuminate and advance our understanding of the nature and structure (e.g., stability) of cognitive and non-cognitive processes.

\subsection{Prior Academic Achievement and Self-efficacy and Achievement Goals}

Our proposed regressed structural path from prior academic learning and achievement onto self-efficacy and mastery and performance-approach goal orientations is drawn from previous theoretical tenets (Bandura, 1997) and empirical evidence (Britner \& Pajares, 2006; Lent, Lopez, \& Bieschke, 1991; Liem et al., 2008; Pajares, Johnson, \& Usher, 2007; Phan, 2011c). From a social cognitive perspective, individuals' self-efficacy beliefs are 
formed predominantly from personal enactive learning performances. Enactive performance accomplishments, derived from authentic experiential base, are the most influential source of information on individuals' self-efficacy beliefs. Performance-based successes in the face of adversity build a high sense of personal efficacy, whereas failures weaken and undermine self-efficacy especially when they occur at an early onset with early repeated failures having an adverse effect on the individual.

The prior academic achievement - efficacy relation is consistent and relatively clear (Bandura, 1997), whereas the possible effects of a student's enactive learning experience on his/her achievement goal orientations require further examination. We do not know, for example, whether successful accomplishments in the completion of a task (e.g., satisfactorily completing 10 arithmetic questions involving algebraic equations) or a unit (e.g., satisfactorily obtaining an "A" grade with the calculus unit) make any difference to one's own orientations towards a particular achievement goal (e.g., mastery). Achievement in learning is based, in part, on normative evaluation and social comparison with others; however, one could also say that individuals' performances are subject to mastery criteria (e.g., "Can I successfully complete this task" YES/NO) and personal growth. Consequently, similar to personal self-efficacy, we query whether repeated successes, say, may shape the initial states and influences' subsequent trajectories in mastery and performance-approach goal orientations.

\subsection{Self-efficacy, Achievement Goals, and Academic Achievement}

From a longitudinal perspective, the study of prior academic achievement, self-efficacy, achievement goals, and current academic achievement can be studied in totality. Unlike previous cross-sectional (e.g., Liem et al., 2008; Pajares, 1996a; Pajares \& Graham, 1999; Pajares \& Kranzler, 1995; Pajares \& Miller, 1994) and longitudinal (Bong, 2002; Phan, 2009b, 2011a; Skaalvik \& Rankin, 1998) studies, our integrated focus is more than just the establishment and validation of structural relations between theoretical variables (e.g., mastery goal $\rightarrow$ academic achievement). This examination of growth modeling testing (McArdle \& Nesselroade, 2003) may provide methodological insight into the possible effects of change on to students' academic achievements. Rather than ascertaining proximal and temporal predictive effects, the conceptualization here details questions pertaining to the importance of stability/instability - for example: does one's own decline in self-efficacy beliefs lead to poor academic outcomes eventually?; and how does one's increasing inclination towards a mastery goal relate to his/her achievement in mathematic?

\subsection{The Present Study: An Amalgamated Framework of Evaluation and Testing}

The present study then, in conjunction with existing research evidence, involves the testing of a number of structural relations between prior academic achievement, self-efficacy, achievement goals, and achievement in mathematics. Based on similar analyses in previous LGM studies (e.g., Kim \& Cicchetti, 2006; Odgers et al., 2009), our postulation includes the following structural paths:

1) Prior academic achievement exerts positive effects on academic achievement, and the initial state and rate of change of rate for self-efficacy, mastery and performance-approach goals.

2) The intercept factor of self-efficacy exerts positive effects on academic achievement, and the rate of change for mastery and performance-approach goals.

3) The intercept factor of mastery goals exerts positive effects on academic achievement, and the rate of change for self-efficacy and performance-approach goals.

4) The intercept factor of performance-approach goals exerts positive effects on academic achievement, and the rate of change for self-efficacy and mastery goals.

5) Correlations are specified for intercept (e.g., self-efficacy and mastery goals) and slope (e.g., self-efficacy and mastery goals) factors.

\section{Method}

\subsection{Participants}

Participants were 228 (106 females, 122 males) first-year university students enrolled in a university in the Asia-Pacific region. The administration of the questionnaires and the collection of data were as follows: $\mathrm{T}_{1}-$ prior academic results for mathematic (Unit Mat100) were collected in mid-December of first year of university; self-efficacy, mastery and performance-approach goal orientation measured at the end of January, $\mathrm{T}_{2}$, the end of April, $T_{3}$, the end of August, $T_{4}$, and the end of November, $T_{5}$, of second year of university; $T_{6}$ - end-of-year mathematic results (Unit Mat200), the first week of December in second year of university. The specification of prior academic achievement at $T_{1}$ and final academic achievement at $T_{6}$ was deliberately set in order for us to validate the possible temporally displaced effects of prior academic achievement and mastery and 
performance-approach goals.

\subsection{Instruments}

Academic self-efficacy. Eight items of the self-efficacy subscale of the Motivated Strategies and Learning Questionnaire (MSLQ) (Pintrich, Smith, Garcia, \& McKeachie, 1991; Pintrich, Smith, Garcia, \& McKeachie, 1993) were answered on a seven-point Likert-type rating scale: $1=$ "not at all true of me" to $7=$ "very true of me". In the process of answering this questionnaire for the two occasions, Time 2 and Time 3, we asked the participants to situate their responses with reference to mathematic. Items include, for example: "I'm certain that I can understand what is taught in mathematic" and "I believe I will receive excellent marks in mathematic".

Achievement goals. The items for mastery (6 items) and performance-approach (6 items) reported in the Midgley, et al. (1998) article. Sample items included, for example: "An important reason I do my work in mathematic is because I enjoy it" (mastery scale); and "Doing better than other students in this mathematic is important to me" (performance-approach scale). Participants completed the two scales by indicating their agreement with each of the 10 items on a seven-point scale ranging from 1 ("strongly disagree") to 7 ("strongly agree"). We modified a few wordings to suit the context of university studies in mathematic.

Mathematic achievement. Academic achievement in mathematic in second year, Unit Mat200, was measured by using two indexes: participant's course work marks for mathematic $(50 \%)$ and their final mathematic exam results. Prior academic achievement in first year mathematic, similar to mathematic achievement, was measured by using two indexes from Unit Mat100: course work marks (50\%) and final mathematic exam results (50\%). Furthermore, the contents are similar for both units, Mat100 and Mat200, with the former unit serving as a prerequisite.

\subsection{Procedure}

Instruments were administered in tutorial classes with the assistance of two assistants. Participation was voluntary and no remuneration was provided. We gave each participant an ID number (i.e., starting with $001 \mathrm{~A}, \ldots .$.$) and, in turn, explained to the total cohort the purpose of this number and the overall study, in general.$ Consequently, in assuring the issue of anonymity, we informed the participants the main protocols regarding confidentiality - that is, responses to the inventories would be locked in our offices and only the statistician analyzing the data would have access to this data.

\section{Results}

LGM is advantageous as it enables the study and testing of possible growth in repeated measures over time (Bollen \& Curran, 2006; Duncan et al., 1999; McArdle \& Nesselroade, 2003). To determine the shape of trajectories for the entire sample, we used LISREL to test three alternative models: (i) a no-growth model, model $\mathrm{M}_{0}$, where no slope component was assumed; (ii) a linear growth model, model $\mathrm{M}_{1}$, where we assumed a linear pattern of change over time and fixed values of slope parameters as $\mathrm{A}\left[\mathrm{t}_{1}\right]=0, \mathrm{~A}\left[\mathrm{t}_{2}\right]=1, \mathrm{~A}\left[\mathrm{t}_{3}\right]=2$, and $\mathrm{A}\left[\mathrm{t}_{4}\right]=3$; and iii) a non-linear growth model, model $\mathrm{M}_{2}$, where the form of change over time is not specified a priori. With the non-linear growth model, the slope parameter for the first occasion was fixed to $0\left(\mathrm{~A}\left[\mathrm{t}_{1}\right]=0\right)$ to allow a separation of the intercept and slope components, and the slope parameter for the last occasion was fixed to 1 $\left(\mathrm{A}\left[\mathrm{t}_{4}\right]=1\right)$ to provide a scale of measurement for the slopes. The slope parameters for the second and third occasions were freely estimated from the data.

A number of goodness-of-fit index values are provided by LISREL include, for example, the Chi-square statistic $\left(\chi^{2}\right)$, the Steiger-Lind root mean square error of approximation (RMSEA) (Steiger, 1990) with its $90 \%$ confidence interval, and the Bentler Comparative Fit Index (CFI) (Bentler, 1990), the Non-normed Fit Index (NNFI) (Bentler \& Bonett, 1980). Conventionally, models with CFI and NNFI values over .90 and RMSEA values below .06 are normally considered as being acceptable in fit (Byrne, 1998; Kline, 2011; Schumacker \& Lomax, 2004). In the subsequent sections, we report the $\chi^{2}$ statistics, CFI, NNFI, and RMSEA.

\subsection{Multivariate Growth Curve Analysis}

Reliability values, means and standard deviations for prior academic achievement at $T_{1}$, self-efficacy, mastery and performance-approach goals at $\mathrm{T}_{3}$ to $\mathrm{T}_{5}$, and mathematic achievement at $\mathrm{T}_{6}$ are presented in Table 1. In our preliminary analyses, we noted that the kurtosis values for the measured indicators ranged from -.85 to 1.12 , and the skewness values ranged from -.57 to .96 ; these values indicate a normal distribution of the data (Kline, 2005).

Table 2 shows the goodness-of-fit index values for the different a priori models tested. Our initial analysis of the no-growth model $\left(\right.$ Model $\left.\mathrm{M}_{0}\right)$ showed an average model fit $\left(\chi^{2}{ }_{(75)}=196.50, \mathrm{CFI}=.93\right.$, NNFI $=.92$, RMSEA 
$=.10$ ). A comparison of goodness-of-fit values between the subsequent models showed that the non-linear growth model, model $\mathrm{M}_{2}$, was a better-fit model $\left(\chi_{(63)}^{2}=82.32\right.$, CFI $=.99$, NNFI $=.99$, RMSEA $\left.=.04\right)$ than the linear growth model, model $\mathrm{M}_{1}$; the chi-square difference test also supported this claim $\left(\Delta \chi^{2}{ }_{(\mathrm{M} 2-\mathrm{M} 1)}(6, N=228)\right.$ $=14.54, p<.025)$. With the non-linear growth model, we extended our analyses to include another non-linear growth model, model $\mathrm{M}_{3}$, where no correlations were made for the intercept and slope factors between self-efficacy, mastery and performance-approach goals (e.g., the self-efficacy intercept factor and the performance-approach intercept; the intercept and slope factors of self-efficacy). The goodness-of-fit index values $\left(\chi_{(72)}^{2}=283.01, \mathrm{CFI}=.93, \mathrm{NNFI}=.90, \mathrm{RMSEA}=.11\right)$ and the chi-square difference test $\left(\Delta \chi_{(\mathrm{M} 2-\mathrm{M} 3)}^{2}(9\right.$, $N=228)=200.69, p<.001)$ provided additional support for the acceptance of the non-linear growth model, model $\mathrm{M}_{2}$.

Table 1. Means, standard deviations, and reliabilities

\begin{tabular}{lllll}
\hline Constructs & Total & Females & Males & Reliability \\
\hline Self-efficacy $-\mathrm{T}_{1}$ & $4.84(1.48)$ & $4.62(1.48)$ & $5.03(1.45)$ & .74 \\
Self-efficacy $-\mathrm{T}_{2}$ & $4.71(1.70)$ & $4.45(1.64)$ & $4.93(1.72)$ & .80 \\
Self-efficacy $-\mathrm{T}_{3}$ & $4.63(1.80)$ & $4.45(1.77)$ & $4.79(1.82)$ & .81 \\
Self-efficacy $-\mathrm{T}_{4}$ & $4.95(1.80)$ & $4.74(1.50)$ & $5.13(1.53)$ & .79 \\
Mastery $-\mathrm{T}_{1}$ & $4.66(1.80)$ & $4.63(1.69)$ & $4.68(1.89)$ & .82 \\
Mastery $-\mathrm{T}_{2}$ & $4.60(1.68)$ & $4.50(1.67)$ & $4.66(1.69)$ & .80 \\
Mastery $-\mathrm{T}_{3}$ & $4.83(1.90)$ & $4.75(1.75)$ & $4.90(2.02)$ & .81 \\
Mastery $-\mathrm{T}_{4}$ & $5.07(1.74)$ & $5.02(1.66)$ & $5.11(1.80)$ & .78 \\
Performance-approach $-\mathrm{T}_{1}$ & $4.94(1.54)$ & $4.83(1.44)$ & $5.03(1.62)$ & .75 \\
Performance-approach $-\mathrm{T}_{2}$ & $4.93(1.60)$ & $4.71(1.50)$ & $5.13(1.67)$ & .77 \\
Performance-approach $-\mathrm{T}_{3}$ & $4.88(1.81)$ & $4.58(1.75)$ & $5.14(1.84)$ & .80 \\
Performance-approach $-\mathrm{T}_{4}$ & $4.79(1.66)$ & $4.60(1.58)$ & $4.95(1.71)$ & .79 \\
Prior academic achievement & $59.41(8.84)$ & $60.35(7.38)$ & $58.49(9.88)$ & \\
Maths Course mark & $65.30(9.31)$ & $61.22(12.00)$ & $62.38(11.93)$ & \\
Maths Exam mark & $61.84(11.95)$ & $66.22(8.78)$ & $64.50(9.72)$ & \\
\hline
\end{tabular}

Note. Standard deviations are in brackets

Table 2. Goodness-of-fit index values

\begin{tabular}{lllllllll}
\hline Descriptions & $\chi^{2}$ & $\mathrm{~d} f$ & CFI & NNFI & RMSEA & $\Delta \chi^{2}$ & $\Delta \mathrm{d} f$ & $p(\mathrm{~d})$ \\
\hline Model $\mathrm{M}_{0}$ & 196.50 & 75 & .93 & .92 & .10 & - & & \\
Model $\mathrm{M}_{1}$ & 96.86 & 69 & .99 & .98 & .04 & 99.64 & 6 & .001 \\
Model $\mathrm{M}_{2}$ & 82.32 & 63 & .99 & .99 & .04 & 14.54 & 6 & .025 \\
Model $\mathrm{M}_{3}$ & 283.01 & 72 & .93 & .90 & .11 & 200.69 & 9 & .001 \\
\hline
\end{tabular}

Examination of parameter estimates from Table 3 indicated five statistically significant structural paths: the effects of prior academic achievement on the intercept factors of self-efficacy $(\mathrm{B}=.48, S E=.11, p<.001)$, mastery $(\mathrm{B}=.57, S E=.12, p<.001)$, and performance-approach $(\mathrm{B}=.41, S E=.11, p<.001)$ goals; the negative effect of prior academic achievement on the slope factor of mastery goals mastery $(\mathrm{B}=-.36, S E=.09, p$ $<.001)$; and the effect of prior academic achievement on academic achievement mastery $(\mathrm{B}=.30, S E=.09, p$ $<.01)$.

For a mastery goal orientation, significant variance of both intercept $\left(\sigma^{2}=2.17, S E=.29, p<.001\right)$ and slope $\left(\sigma^{2}\right.$ $=.88, S E=.24, p<.001)$ indicated the presence of significant individual difference in initial levels and change in mastery goals. Both intercept mean $(M=1.20, p<.001)$ and the slope mean $(M=2.31, p<.001)$ were 
significantly different from zero, indicating that students' mastery goal orientation increased over time. A similar pattern was also noted for a performance-approach goal orientation, with statistically significant variance for both intercept $\left(\sigma^{2}=1.79, S E=.22, p<.001\right)$ and slope $\left(\sigma^{2}=.83, S E=.18, p<.001\right)$ factors. Both intercept mean $(M=2.51, p<.001)$ and slope mean $(M=.46, p<.001)$ were positive and significantly different from zero, suggesting that students' performance-approach goal orientation increased over time. Finally for self-efficacy, significant variance of both intercept $\left(\sigma^{2}=1.65, S E=.21, p<.001\right)$ and slope $\left(\sigma^{2}=.37, S E=.17, p<.05\right)$ indicated the presence of significant individual difference in initial levels and change in self-efficacy. Both intercept mean $(M=2.02, p<.001)$ and the slope mean $(M=.77, p<.001)$ were significantly different from zero, indicating that students' self-efficacy beliefs increased over time. The intercept factor of mastery goals was positively related to the intercept factors of performance-approach goals $(\mathrm{B}=1.28, S E=.18, p<.001)$ and self-efficacy $(\mathrm{B}=1.17, S E=.17, p<.001)$. Similarly, a positive association was noted for the intercept factors of both self-efficacy and performance-approach goals $(\mathrm{B}=1.21, S E=.16, p<.001)$. Overall, Figure 2 shows the trajectories of self-efficacy, mastery and performance-approach goals over the four occasions for the learning of mathematic.

Table 3. Parameter estimates, Standard errors, and Critical ratios for multivariate growth curve model

\begin{tabular}{|c|c|c|c|c|}
\hline & Estimate & & Std. error & Critical ratio \\
\hline \multicolumn{5}{|l|}{ Factor loadings } \\
\hline Time $1 \rightarrow$ Self-efficacy slope & $0=$ & & & \\
\hline Time $2 \rightarrow$ Self-efficacy slope & $=$ & & & \\
\hline Time $3 \rightarrow$ Self-efficacy slope & $=$ & & & \\
\hline Time $4 \rightarrow$ Self-efficacy slope & $1=$ & & & \\
\hline Time $1 \rightarrow$ Mastery slope & $0=$ & & & \\
\hline Time $2 \rightarrow$ Mastery slope & $=$ & & & \\
\hline Time $3 \rightarrow$ Mastery slope & $=$ & & & \\
\hline Time $4 \rightarrow$ Mastery slope & $1=$ & & & \\
\hline Time $1 \rightarrow$ Performance-approach slope & $0=$ & & & \\
\hline Time $2 \rightarrow$ Performance-approach slope & $=$ & & & \\
\hline Time $3 \rightarrow$ Performance-approach slope & $=$ & & & \\
\hline Time $4 \rightarrow$ Performance-approach slope & $1=$ & & & \\
\hline \multicolumn{5}{|l|}{ Regression effects on intercept } \\
\hline Prior acad achievement $\rightarrow$ Self-efficacy intercept & .48 & $* * *$ & .11 & 4.43 \\
\hline Prior acad achievement $\rightarrow$ Mastery intercept & .57 & $* * *$ & .12 & 4.74 \\
\hline $\begin{array}{l}\text { Prior acad achievement } \rightarrow \text { Performance-approach } \\
\text { intercept }\end{array}$ & .41 & $* * *$ & .11 & 3.72 \\
\hline \multicolumn{5}{|l|}{ Regression effects on slope } \\
\hline Prior acad achievement $\rightarrow$ Self-efficacy slope & -.12 & & .08 & -1.49 \\
\hline Mastery intercept $\rightarrow$ Self-efficacy slope & .10 & & .07 & .17 \\
\hline Performance-approach intercept $\rightarrow$ Self-efficacy slope & -.13 & & .08 & -1.60 \\
\hline Prior acad achievement $\rightarrow$ Mastery slope & -.36 & $* * *$ & .09 & -3.79 \\
\hline Self-efficacy intercept $\rightarrow$ Mastery slope & .06 & & .11 & .53 \\
\hline Performance-approach intercept $\rightarrow$ Mastery slope & .05 & & .11 & .42 \\
\hline $\begin{array}{l}\text { Prior acad achievement } \rightarrow \text { Performance-approach } \\
\text { slope }\end{array}$ & -.13 & & .09 & -1.44 \\
\hline Self-efficacy intercept $\rightarrow$ Performance-approach slope & -.03 & & .09 & -.35 \\
\hline Mastery intercept $\rightarrow$ Performance-approach slope & .08 & & .08 & 1.02 \\
\hline
\end{tabular}




\begin{tabular}{|c|c|c|c|c|}
\hline \multicolumn{5}{|l|}{ Regression effects on academic achievement } \\
\hline Prior acad achievement & .30 & $* *$ & .09 & 3.31 \\
\hline Self-efficacy intercept & .10 & & .20 & .87 \\
\hline Self-efficacy slope & .17 & & .20 & .87 \\
\hline Mastery intercept & .09 & & .07 & 1.18 \\
\hline Mastery slope & .12 & & .09 & 1.34 \\
\hline Performance-approach intercept & .16 & & .11 & 1.37 \\
\hline Performance-approach slope & -.05 & & .10 & -.52 \\
\hline \multicolumn{5}{|l|}{ Factor variances } \\
\hline Self-efficacy intercept & 1.65 & $* * *$ & .21 & 7.79 \\
\hline Self-efficacy slope & .37 & * & .17 & 2.24 \\
\hline Mastery intercept & 2.17 & $* * *$ & .29 & 7.43 \\
\hline Mastery slope & .88 & $* * *$ & .24 & 3.69 \\
\hline Performance-approach intercept & 1.79 & $* * *$ & .22 & 8.21 \\
\hline Performance-approach slope & .83 & $* * *$ & .18 & 4.59 \\
\hline \multicolumn{5}{|l|}{ Factor covariances } \\
\hline Self-efficacy intercept $\leftrightarrow$ Self-efficacy slope & .07 & & .13 & .54 \\
\hline Mastery intercept $\leftrightarrow$ Mastery slope & -.20 & & .22 & -.94 \\
\hline $\begin{array}{ll}\text { Performance-approach } & \text { intercept } \\
\text { Performance-approach slope } & \end{array}$ & -.06 & & .14 & -.42 \\
\hline Mastery slope $\leftrightarrow$ Performance-approach slope & .04 & & .08 & .51 \\
\hline Mastery slope $\leftrightarrow$ Self-efficacy slope & .06 & & .08 & .72 \\
\hline Self-efficacy slope $\leftrightarrow$ Performance-approach slope & .11 & & .07 & 1.48 \\
\hline Mastery intercept $\leftrightarrow$ Performance-approach intercept & 1.28 & $* * *$ & .18 & 7.22 \\
\hline Mastery intercept $\leftrightarrow$ Self-efficacy intercept & 1.17 & $* * *$ & .17 & 6.87 \\
\hline $\begin{array}{l}\text { Self-efficacy intercept } \leftrightarrow \text { Performance-approach } \\
\text { intercept }\end{array}$ & 1.21 & $* * *$ & .16 & 7.57 \\
\hline
\end{tabular}

Note. ${ }^{*} p<.05,{ }^{* *} p<.01,{ }^{* * *} p<.001$.

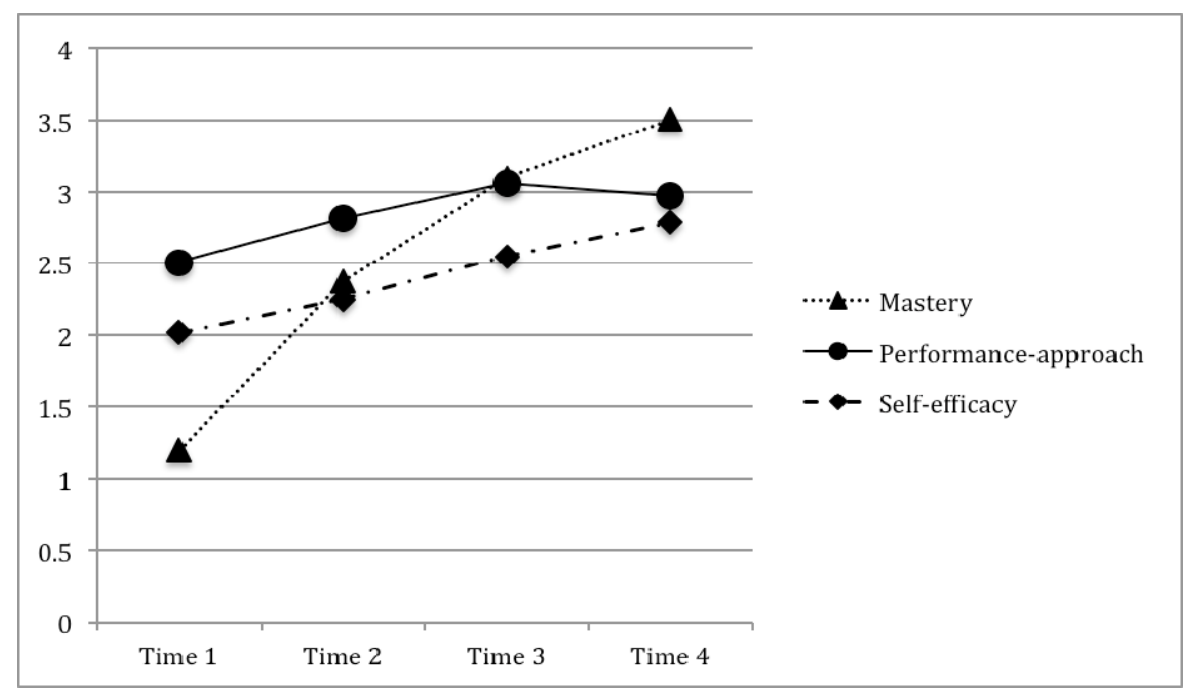

Figure 2. Final trajectories of self-efficacy, mastery, and performance-approach goals 


\section{Discussion}

This research study examined the developmental trajectories of self-efficacy and achievement goals in the subject area of mathematic. Furthermore, our examination involved the specification and regression of prior academic achievement as a possible antecedent of self-efficacy and mastery and performance-approach goal orientations. One notable aspect of our research, differing from previous investigations (Chouinard, Karsenti, \& Roy, 2007; Diseth, 2011; Liem et al., 2008; Pajares \& Miller, 1994; Phan, 2009a, 2010b), entailed a longitudinal focus in hypotheses and statistical testing. In general, the findings ascertained from multivariate growth modeling analyses support our hypothesized structural relations and previous theoretical tenets of the two theoretical frameworks. In this section of the article, we discuss the findings ascertained in relation to applied teaching practices for educators and teacher alike.

\subsection{Trajectories of Self-efficacy and Achievement Goals}

Inspection of the graph reported in Figure 2 indicates increase in growth of personal self-efficacy, mastery, and performance-approach goal orientations. Visually, there is a relatively steeper slope in change for a mastery goal orientation than that of personal self-efficacy or a performance-approach goal. Despite this small disparity, there is consistency in the rates of trajectories of the three constructs and this increase illuminates an important milestone during the undergraduate years. The evidence we obtained portrays a course of behavior and action that students may, collectively, manifest in their undergraduate studies. It is plausible to suggest that successful ongoing learning experiences at university, for example, may compel students to orientate towards a performance-approach goal orientation. In a similar vein, in-depth knowledge, interest, and intellectual curiosity may also instill ongoing positive self-efficacy beliefs for academic learning. Strengthened self-efficacy beliefs may, consequently, facilitate and mobilize students to seek more mastery in their learning and development of skills.

Other factors may also contribute to the increase in rates of change of self-efficacy, mastery, and performance-approach goals. Notably, we contend that the positive values placed in learning may stimulate and motivate students to expend more effort, and to resort to alternative cognitive strategies (e.g., deep learning approach) in their studies. Consistent with the task value component of the expectancy-value theoretical framework (e.g., Eccles et al., 1983; Wigfield, 1994; Wigfield \& Eccles, 2000), students' positive perceptions and valuing of engagement in a particular subject matter (e.g., "I feel really good about this subject, mathematic; I can see how this will relate to what I do later on") may account for behaviors and outcomes that accentuate the importance of deep, meaningful, and mastery learning. Similarly, one aspect for future consideration is the study and validation of other extraneous variables that could account for the varying patterns in trajectories of, say, personal self-efficacy beliefs. At present, apart from our emphasis on students' prior learning experiences, there is very little information about the prediction and explanatory powers of other non-achievement related outcomes. It would be of considerable interest, for example, to explore the impact of students' aspirations and long-term objectives on the rate of change of self-efficacy beliefs for learning and academic achievement.

Significantly, from a theoretical point of view, the evidence ascertained illuminates the instability of cognitive and non-cognitive processes in students' learning in higher education contexts. From an educational perspective, arising from this study, we contend that it is important for educators to consider pedagogical strategies and/or instructional policies that may accommodate students' needs to develop mastery and improve on skills and knowledge of key concepts. Notably, given the transient and varying nature of personal self-efficacy and achievement goal orientations, it is still an advantageous feat to consider these two theoretical orientations in students' learning processes.

\subsection{Possible Antecedent of Self-efficacy and Achievement Goals}

We obtained findings that emphasize the predictive effects of prior academic achievement on the intercept factors of self-efficacy, mastery, and performance-approach goals. Successful accomplishments in a mathematic unit, in this case, instill and strengthen students' self-efficacy beliefs for academic learning. Failure, in contrast, weakens students' resolve and self-efficacy beliefs, and could consequently lead to other undesirable outcomes and behaviors. This evidence is in accordance with existing research findings (Britner \& Pajares, 2006; Lent et al., 1991; Liem et al., 2008; Pajares et al., 2007; Phan, 2011c) and Bandura's (1997) theoretical tenets, indicating the potency of enactive learning experiences that may be subject to mastery criteria (e.g., "Am I good enough to obtain a Pass (Pass/No) for this practical component of the unit?"). More importantly, contributing theoretically to the study of self-efficacy, we emphasize the use of students' prior academic results to denote and reflect the notion of enactive performance accomplishments (Liem et al., 2008; Matsui, Matsui, \& Ohnishi, 1990; Phan, 2011c). This methodological approach (i.e., using students' actual performance scores) differs from the 
mentioned studies (e.g., Hampton, 1998; Lent et al., 1991; Lopez \& Lent, 1992) and may, in our view, yield more of an accurate illumination of students' perceptions of their prior learning experiences. Asking a student, for example, to recall his/her prior learning experiences in a particular unit of study (e.g., "I recalled that I was always received good marks in Calculus") may reveal inaccurate judgments and perceptions. This issue of calibration is prevalent in self-efficacy research, and has been explored by a number of researchers (e.g., Pajares, 1996b; Pajares \& Miller, 1994).

Furthermore, similar to the impact on self-efficacy, we note that prior academic achievement exerted positive effects on both goal types. What is interesting, though, is that prior academic achievement influenced the slope of a mastery goal orientation, negatively, but not on self-efficacy or performance-approach goals. Students who reported personal successes in mathematic showed slower rate of increase in mastery goals compared to those who reported failures. This perplexed finding suggests that personal growth and mastery of skills entail some complexities, and may project varying trajectories over the course of learning. Similar to our previous mentioning, apart from personal performance accomplishments, we need to consider other variables that may also account and explain for the changes in achievement goals. For example, it may be commendable to explore the impact of, say, subject matter on students' adoption towards mastery and performance-approach goals. Mathematic is classified as a 'hard pure' subject discipline (Becher, 1987, 1994) and this categorization, in our view, may compel students to orientate towards a particular trajectory in mastery goals. Topical themes such as Algebra and Calculus, for instance, are theoretical in nature and, according to students, demonstrate very little 'relevance' and 'authenticity' to everyday settings (e.g., "How is this topic relevant for me in terms of finding work?"). Initial increase in a mastery goal orientation in mathematic may, consequently, lead to varying patterns that reflect decreases and stability over the course of time.

In a similar vein, we could also consider the nature of learning objectives and assessment tasks and criteria used in a unit that may accentuate disparate learning outcomes (e.g., mastery versus performance). The use of periodic high paced assessment tasks that emphasize normative evaluation in mathematic may, in this instance, encourage a sense of competition and inner desire to achieve academic excellence. Students may focus more predominantly on achievements for public recognition and other related outcomes (e.g., obtaining a score for university entry), rather than personal growth. Consequently, in the course of mathematic learning, students may gradually proceed to orientate towards performance goals. In this analysis, similar to stipulated learning objectives, we may wish to pursue this avenue of inquiry by exploring the possible varying trajectories of achievement goal orientations with different assessment tasks (e.g., an authentic assessment task).

\subsection{Antecedents of Academic Achievement}

We note that, consistent with previous findings (e.g., Liem et al., 2008; Pajares \& Valiante, 1999), prior academic achievement influenced current mathematic achievement. Individual success is more likely to result in an enhancement of academic achievement in mathematic; likewise, prior academic failure weakens one's current achievement. In this sense, personal successes and failures provide fruitful information for the gauging of future performance in academic learning. From an educational perspective, this finding may serve to motivate and reinforce students' positioning to persist in their studies. Repeated failures, for instance, should be perceived and viewed as a source of information for improvement and subsequent accomplishments.

In relation self-efficacy and achievement goals, our analyses yielded inconclusive and null evidence. Some previous research studies have, similarly, reported a null association between a mastery goal orientation (e.g., Dupeyrat \& Mariné, 2005; Fenollar et al., 2007; Liem et al., 2008; Senko \& Miles, 2008; Sins et al., 2008) and performance-approach (Dupeyrat \& Mariné, 2005; Fenollar et al., 2007; Liem et al., 2008) and academic achievement. For self-efficacy, however, the non-statistical significance we obtained is in discord with existing theoretical tenets (Bandura, 1997; Pajares, 1996b) and empirical findings (Pajares \& Kranzler, 1995; e.g., Pajares \& Miller, 1994; Phan, 2009b). The contextualized nature of learning tasks may, in our view, explain for the absence in associations between mastery, performance-approach, and self-efficacy and mathematic achievement. In the area of self-efficacy, for example, there is theoretical emphasis pertaining to the importance of context specificity of self-efficacy (Bandura, 1997). In this sense, according to Bandura (1997), self-efficacy may operate at different levels of specificity - for example: global (e.g., "I feel confident that I have the perceived competence to complete this unit, Mat200"), problem (e.g., "I feel confident that I have the perceived competence to solve the 10 problems in Calculus for this unit, Mat200"), and task (e.g., "I am confident that I have the perceived competence to solve this mathematic problem - ' $4 \cos ^{2} x-1=0$ "'). More importantly, however, explanatory and predictive power of self-efficacy is intricately linked to the tenet of constructive alignment between this construct and academic achievement tasks (e.g., "Solve this mathematical problem: ' $\sqrt{3}$ $\sin x-\cos x=1 " \prime)$. 
The contention then, drawing from the self-efficacy inquiry, is the extent to which the notion of contextualization applies to one's achievement goal orientations. Does the contextualized nature of learning objectives and tasks relate to a student's mastery goal orientation? In particular, we need to consider the assessment and evaluation of both mastery and performance-approach goal orientations (e.g., descriptive open-ended items) within the contexts of learning tasks, objectives, etc. Judgment towards a preference for a specific goal type in educational settings may depend, in part, on the specificity of learning objectives and contents - for example, an orientation towards academic work, in general, versus an orientation towards a need for one to learn and master a new concept.

\subsection{Associations between Self-efficacy and Achievement Goals}

Our findings indicate positive associations between the initial states of mastery and performance-approach goals $(r=.65, p<.001)$, a mastery goal orientation and self-efficacy $(r=.62, p<.001)$, and a performance-approach goal orientation and self-efficacy $(r=.70, p<.001)$. Non-statistically relations for the slope factors of self-efficacy, mastery and performance-approach goals were also noted from our analyses. This evidence, collectively, indicates the potent effects of personal self-efficacy (Bandura, 1997). In the contexts of university learning, as indicated here, a heightened sense of self-efficacy is associated closely with the two types of goal orientations. Students who have positive self-efficacy beliefs about learning a particular subject matter (e.g., specialization in applied mathematic), for example, are more likely to orientate towards mastery (e.g., "I'm really interested to know more about this theme; it's very well-explained and interesting") and personal accomplishments for external purposes (e.g., "I need to obtain a good grade for this course in order for me to consider applying for the job with the UN"). In this sense, cyclically, students who reported a high mastery goal score also scored high self-efficacy and performance-approach goal scores. This pattern in findings is not uncommon, given the three theoretical constructs share a number of comparable characteristics, one of which is concerned with the positive impacts on academic achievement.

From an educational perspective, the interrelations between self-efficacy, mastery, and performance-approach goal orientations suggest a number of implications for applied teaching practices. There is extensive evidence that attests to the practicality of the three mentioned constructs in learning in various educational levels. In the contexts of university learning, for example, it is advantageous to cultivate a social milieu that accentuates the saliency of a mastery goal structure (Anderman \& Midgley, 1997; Urdan, 2004). The use of authentic assessment tasks that emphasize mastery, non-evaluative normative criteria may, for instance, help to stimulate interest and curiosity in students' learning. We may also choose to structure our teaching objectives and pedagogical strategies (e.g., cooperative learning) in order to encourage a non-performance goal orientation (e.g., "I like doing this task; it's really interesting that we get to interact with others to share ideas").

Interestingly, and this requires further emphasis, is the non-statistical significance in slopes between self-efficacy, mastery, and performance-approach goal orientations. To date, there is limited examination in relationships between the three theoretical constructs from a longitudinal perspective. Despite the lack in associations, there are a number of questions that could be asked and advanced for continuing research development. In particular, what is of interest, for example, is an identification and account for the non-statistical relationships between, say, self-efficacy and a mastery goal orientation. What other related factors during the course of students' learning could act in tandem to facilitate an association between self-efficacy and mastery goals? What extraneous factors (e.g., students' valuing of a subject matter) could, similarly, combine with students' self-beliefs (e.g., self-efficacy, self-esteem) to account for the trajectories in achievement goal orientations (e.g., mastery)?

\section{Conclusion}

In conclusion, our research investigation offers theoretical grounding for further conceptualization into the relations between self-efficacy, achievement goals, and academic achievement. In particular, the findings that we obtained provide moderate support for the hypotheses relating to the trajectories of self-efficacy and achievement goals, as well as the role of prior academic achievement as an antecedent of cognitive and non-cognitive process outcomes. One notable aspect of our research investigation, for example, entails theoretical contributions of multiple-goals and multiple-trajectories of goals in university learning.

In the contexts of higher education, students adopt different goals and, consequently, project varied trajectories in the course of their learning. Different psychosocial factors, as well as personal learning experiences may influence students' self-beliefs about learning, and this impact may result in the adoption of different goal trajectories. From an applied teaching perspective, it is important for educators to consider the strengthening of self-efficacy and/or achievement goals (e.g., mastery) periodically by via means of various pedagogical strategies. In the area of self-efficacy, for example, Schunk and his colleagues have devised strategies that 
involved expert modeling (Schunk, 1987; Schunk \& Hanson, 1985, 1989; Schunk, Hanson, \& Cox, 1987) and verbal discourse (e.g., ability: "You're very good at this, Tom!")(Schunk, 1982, 1983, 1984). Researchers have also indicated that the environment at large (classroom, school), conveying different messages to students, makes certain goals for learning salient (Ames, 1992; Lau \& Nie, 2008; Urdan, 2004; Urdan, Kneisel, \& Mason, 1999). Instructional policies relating to assessment tasks implemented, say, at a classroom level may accentuate a particular achievement goal focus; for example, the use of authentic assessment tasks in units is more likely to emphasize a mastery goal structure, encouraging individual growth and mastery of specific skills.

What is important, from a developmental perspective, is the sustaining of positive self-efficacy beliefs for academic learning over time. Mindful of the ongoing trajectories of self-efficacy (increase/decrease), we need to contemplate and encourage different alternatives that may assist learners to maintain their positive inner states and potentials (e.g., "I really positive about myself and what I can do in this unit, ECO101"). In a similar manner, it is of considerable importance for educators to foster and sustain appropriate goal types (e.g., a mastery goal) that could, in effect, stimulate deep and quality learning outcomes. One clear approach, as indicated from our research investigation, is the possible use of enactive performance accomplishments.

Despite the theoretical and methodological contributions made, we also note three major limitations that warrant further conceptualization and research development. Firstly, given our small sample size and the stringent specifications (e.g., a structural path/participants ratio) that LGM procedures stipulate (e.g., Bollen \& Curran, 2006; Duncan et al., 1999; McArdle \& Nesselroade, 2003), we could not include other achievement goal types in this research study. With a larger sample size, researchers could explore the trajectories of performance-avoidance and work-avoidance goals in different educational contexts. Questionably, it is important to compare and contrast the developmental courses of these avoidance goal types to those that may facilitate growth and positive performance outcome. Does the rate of change of, say, performance-avoidance goals decrease over time? What are some of the internal processes or external factors that could account for a decline in performance-avoidance goals?

Secondly, it is important that researchers pursue the study of initial state and rate of change of self-efficacy and achievement goals, taking into consideration the importance of contextualization. Researchers have suggested that the differing nature of subject disciplines may result in students adopting different study processing strategies (Smith \& Miller, 2005). This line of reasoning concerning differences in disciplines arises, in part, from the work of Becher $(1989,1994)$ where the author classified academic disciplines into four broad intellectual categorizations: "hard pure" (e.g., science involving, say, Physics), "soft pure" (e.g., anthropology), "hard applied" (e.g., computing), and "soft applied" (e.g., education). These categorizations entail different forms of knowledge; for example, English, as "soft pure", entails a holistic form of knowledge where learning is concerned with understanding and interpretation of ideas, and the establishment of coherence in structuring and argument (Smith \& Miller, 2005). Mathematics, as "hard pure", consists of knowledge that is cumulative and atomistic, and involves predominantly the learning of specific facts, principles, and concepts. The question then is whether, similar to the inquiry of study processing strategies, students also vary in their formation of self-efficacy or adoption of achievement goals. For example, do students have more inclination towards the adoption of mastery goals when they learn "hard applied" or "soft applied" subject disciplines? Subject disciplines such as Industrial design, textile and technology are more applicable to everyday living, stimulating, perhaps, more interest, intellectual curiosity, and attention. Because of this authentic relevance, we may expect students to feel more positive about their sense of self-efficacy, or to adopt a thinking that is related to mastery learning. Likewise, other "hard pure" subject disciplines may entail teachers using traditional assessment and evaluation methods, thereby by proxy encouraging students to adopt more of a performance-approach in their learning. It is of a theoretical contribution for us to examine, comparatively, the trajectories of self-efficacy and achievement goals in the context of different academic subjects.

Thirdly, methodologically, LGM is a powerful statistical technique that enables us to study rate of growth of theoretical constructs (Bollen \& Curran, 2006; Duncan et al., 1999; McArdle \& Nesselroade, 2003). In our research investigation, we examined the rate of change of self-efficacy and achievement goals over a period of four time points $\left(T_{2}-T_{5}\right)$. Ideally, from a theoretical point of view, it is important we consider additional time points of data collection and/or total time period. Developmentally, a two-year period may not provide an adequate picture of how academic self-efficacy changes its course. We noted in our investigation the instability of self-efficacy beliefs and achievement goals, but other unexpected trajectories could also eventuate. It would be of considerable interest, for example, for researchers to explore the developmental courses of students' self-efficacy beliefs and achievement goals over a transitioning period between the upper secondary school years and university. The transitioning period between undergraduate and postgraduate studies is also interesting, 
given completion of the former period of studies may provide students with enriching learning experiences and cognitive maturity.

Having said this we do note, however, that in social sciences research, ethical considerations and logistic reasoning often prevent researchers from engaging in longer periods of examination of theoretical constructs. One possible avenue of inquiry, in this instance, may entail qualitative emphases of students' internal cognitive (e.g., a mastery goal orientation) and non-cognitive (e.g., personal self-efficacy) processes in situ. In particular, rather than stipulating a formal process of administration and collection of data, researchers and/or educators could document students' self-efficacy beliefs and learning, say, in naturalistic classroom settings, periodically. This methodological approach may, in this analysis, provide more enriching information pertaining to the underlying trajectories of personal self-efficacy and other theoretical variables.

\section{References}

Ames, C. (1992). Classrooms: Goals, structures, and student motivation. Journal of Educational Psychology, 84, 261-271. http://dx.doi.org/10.1037/0022-0663.84.3.261

Ames, C., \& Archer, J. (1988). Achievement goals in the classroom: Students' learning strategies and motivation processes. Journal of Educational Psychology, 80, 260-267. http://dx.doi.org/10.1037/0022-0663.80.3.260

Anderman, E., \& Midgley, C. (1997). Changes in personal achievement goals and the perceived classroom goal structures across the transition to middle level schools. Contemporary Educational Psychology, 22, 269-298. http://dx.doi.org/10.1006/ceps.1996.0926

Archer, J. (1994). Achievement goals as a measure of motivation in university students. Contemporary Educational Psychology, 19, 430-446. http://dx.doi.org/10.1006/ceps.1994.1031

Bandura, A. (1986). Social foundations of thought and action: A social cognitive theory. New Jersey: Prentice-Hall, Inc.

Bandura, A. (1997). Self-efficacy: The exercise of control. New York: W. H. Freeman \& Co.

Becher, T. (1987). The disciplinary shaping of the professions. In B. R. Clarke (Ed.), The academic profession. Berkley, CA: University of California Press.

Becher, T. (1994). The significance of disciplinary differences. Studies in Higher Education, 19, 151-161. http://dx.doi.org/10.1080/03075079412331382007

Bentler, P. M. (1990). Comparative fit indexes in structural models. Psychological Bulletin, 107, 238-246. http://dx.doi.org/10.1037/0033-2909.107.2.238

Bentler, P. M., \& Bonett, D. G. (1980). Significance tests and goodness of fit in the analysis of covariance structures. Psychological Bulletin, 88, 588-606. http://dx.doi.org/10.1037/0033-2909.88.3.588

Bollen, K. A., \& Curran, P. J. (2006). Latent curve models: A structural equation perspective. Hoboken, NJ: Wiley.

Bong, M. (2002). Stability and structure of self-efficacy, task-value, and achievement goals and consistency of their relations across specific and general academic contexts and across the school year. Paper presented at the American Educational Research Association (AERA). New Orleans, LA, 2002, New Orleans, LA.

Britner, S. L., \& Pajares, F. (2006). Sources of science self-efficacy beliefs of middle school students. Journal of Research in Science Teaching, 43, 485-499. http://dx.doi.org/10.1002/tea.20131

Byrne, B. M. (1998). Structural equation modelling with LISREL, PRELIS, and SIMPLIS. Mahwah, NJ: Erlbaum.

Caprara, G. V., Fida, R., Vecchione, M., Del Bove, G., Vecchio, G. M., Barbaranelli, C., \& Bandura, A. (2008). Longitudinal analysis of the role of perceived self-efficacy for self-regulated learning in academic continuance and achievement. Journal of Educational Psychology, 100(3), 525-534. http://dx.doi.org/10.1037/0022-0663.100.3.525

Chouinard, R., Karsenti, T., \& Roy, N. (2007). Relations among competence beliefs, utility value, achievement goals, and effort in mathematics. British Journal of Educational Psychology, 77, 501-517. http://dx.doi.org/10.1348/000709906X133589

Church, M. A., Elliot, A. J., \& Gable, S. L. (2001). Perceptions of classroom environment, achievement goals, and achievement outcomes. Journal of Educational Psychology, 93, 43-54. http://dx.doi.org/10.1037/0022-0663.93.1.43 
Diseth, Å. (2011). Self-efficacy, goal orientations and learning strategies as mediators between preceding and subsequent academic achievement. Learning and Individual Differences, 21(2), 191-195. http://dx.doi.org/10.1016/j.lindif.2011.01.003

Duncan, T. E., Duncan, S. C., Strycker, L. A., Li, F., \& Alpert, A. (1999). An introduction to latent variable growth curve modelling: Concepts, issues, and applications. Mahwah, NJ: Erlbaum.

Duncan, T. E., Duncan, S. C., Stycker, L. A., Fuzhong, L., \& Alpert, A. (1999). An introduction to latent variable growth curve modelling: Concepts, issues, and applications. Mahwah, NJ: Erlbaum.

Dupeyrat, C., \& Mariné, C. (2005). Implicit theories of intelligence, goal orientation, cognitive engagement, and achievement: A test of Dweck's model with returning to school adults. Contemporary Educational Psychology, 30, 43-59. http://dx.doi.org/10.1016/j.cedpsych.2004.01.007

Durik, A. M., Lovejoy, C. M., \& Johnson, S. J. (2009). A longitudinal study of achievement goals for college in general: Predicting cumulative GPA and diversity in course selection. Contemporary Educational Psychology, 34, 113-119. http://dx.doi.org/10.1016/j.cedpsych.2008.11.002

Dweck, C. S., \& Leggett, E. L. (1988). A social-cognitive approach to motivation and personality. Psychological Review, 95, 256 - 273. http://dx.doi.org/10.1037/0033-295X.95.2.256

Eccles, J. S., Adler, T. F., Futterman, R., Goff, S. B., Kaczala, C. M., Meece, J. L., \& Midgley, C. (1983). Expectancies, values and academic behaviors. In J. T. Spence (Ed.), Achievement and achievement motives (pp. 75-146). San Francisco: W. H. Freemen.

Elliot, A. J. (1999). Approach and avoidance motivation and achievement goals. Educational Psychologist, 34, 169-189. http://dx.doi.org/10.1207/s15326985ep3403_3

Elliot, A. J., \& Church, M. A. (1997). A hierarchical model of approach and avoidance achievement motivation. Journal of Personality and Social Psychology, 72, 218-232. http://dx.doi.org/10.1037/0022-3514.72.1.218

Elliot, A. J., \& Harackiewicz, J. M. (1996). Approach and avoidance achievement goals and intrinsic motivation: A mediational analysis. Journal of Personality and Social Psychology, 70, 461-475. http://dx.doi.org/10.1037/0022-3514.70.3.461

Elliot, A. J., \& McGregor, H. A. (2001). A 2 x 2 achievement goal framework. Journal of Personality and Social Psychology, 80, 501-519. http://dx.doi.org/10.1037/0022-3514.80.3.501

Elliot, A. J., McGregor, H. A., \& Gable, S. (1999). Achievement goals, study strategies, and exam performances: A mediational analysis. Journal of Educational Psychology, 91, 549-563. http://dx.doi.org/10.1037/0022-0663.91.3.549

Elliot, A. J., \& Murayama, K. (2008). On the measurement of achievement goals: Critique, illustration, and $\begin{array}{lllll}\text { application. Journal of Educational Psychology, 100(3), 613-628. } & \end{array}$ http://dx.doi.org/10.1037/0022-0663.100.3.613

Elliott, E. S., \& Dweck, C. S. (1988). Goals: An approach to motivation and achievement. Journal of Personality and Social Psychology, 54, 5-12. http://dx.doi.org/10.1037/0022-3514.54.1.5

Fenollar, P., Román, S., \& Cuestas, P. J. (2007). University students' academic performance: An integrative conceptual framework and empirical analysis. British Journal of Educational Psychology, 77, 873-891. http://dx.doi.org/10.1348/000709907X189118

Hampton, N. (1998). Sources of academic self-efficacy scale: An assessment tool for rehabitation counselors. Rehabilitation Counseling Bulletin, 41(4), 374-389.

Hancock, G. R., \& Lawrence, F. R. (2006). Using latent growth models to evaluate longitudinal change. In G. R. Hancock \& R. O. Mueller (Eds.), Structural equation modeling: A second course (pp. 171-196). Greenwich, Connecticut: Information Age Publishing.

Harackiewicz, J. M., Barron, K. E., Carter, S. M., Letho, A. T., \& Elliot, A. J. (1997). Predictors and consequences of achievement goals in the college classrooms: Maintaining interest and making the grade.

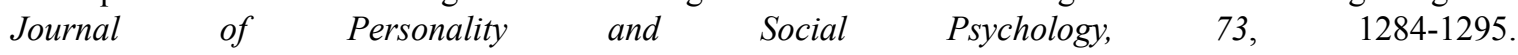
http://dx.doi.org/10.1037/0022-3514.73.6.1284

Harackiewicz, J. M., Barron, K. E., \& Elliot, A. J. (1998). Rethinking achievement goals: When are they adaptive for college students and why? Educational Psychologist, 33(1), 1-21. http://dx.doi.org/10.1207/s15326985ep3301_1 
Harackiewicz, J. M., Barron, K. E., Pintrich, P. R., Elliot, A. J., \& Trash, T. M. (2002). Revision of achievement goal theory: Necessary and illuminating. Journal of Educational Psychology, 94, 638-645. http://dx.doi.org/10.1037/0022-0663.94.3.638

Harackiewicz, J. M., Barron, K. E., Tauer, J. M., Carter, S. M., \& Elliot, A. J. (2000). Short-term and long-term consequences of achievement goals: Predicting interest and performance over time. Journal of Educational Psychology, 92(2), 316-330. http://dx.doi.org/10.1037/0022-0663.94.3.638

Harackiewicz, J. M., Barron, K. E., Tauer, J. M., \& Elliot, A. J. (2002). Predicting success in college: A longitudinal study of achievement goals and ability measures as predictors of interest and performance from freshman year through graduation. Journal of Educational Psychology, 94, 562-575. http://dx.doi.org/10.1037/0022-0663.94.3.562

Harter, S. (1996). Teacher and classmate influences on scholastic motivation, self-esteem, and level of voice in adolescents. In J. Juvonen \& K. R. Wentzel (Eds.), Social motivation: Understanding children's school adjustment (pp. 11-42). Cambridge, England: Cambridge University Press.

Kim, J., \& Cicchetti, D. (2006). Longitudinal trajectories of self-system processes and depressive symptoms among maltreated and nonmaltreated children. Child Development, 77, 624-639. http://dx.doi.org/10.1111/j.1467-8624.2006.00894.x

Kline, R. B. (2005). Principles and practice of structural equation modelling (2nd ed.). New York: Guildford.

Kline, R. B. (2011). Principles and practice of structural equation modeling (3rd ed.). New York, NY: The Guilford Press.

Lau, S., \& Nie, Y. (2008). Interplay between personal goals and classroom goal structures in predicting student outcomes: A multilevel analysis of person-context interactions. Journal of educational Psychology, 100(1), 15-29. http://dx.doi.org/10.1037/0022-0663.100.1.15

Lent, R. W., Lopez, F. G., \& Bieschke, K. J. (1991). Mathematics self-efficacy: Sources and relation to science-based career choice. Journal of Counseling Psychology, 38, 424-430. http://dx.doi.org/10.1037/0022-0167.38.4.424

Liem, A. D., Lau, S., \& Nie, Y. (2008). The role of self-efficacy, task value, and achievement goals in predicting learning strategies, task disengagement, peer relationship, and achievement outcome. Contemporary Educational Psychology, 33, 486-512. http://dx.doi.org/10.1016/j.cedpsych.2007.08.001

Lopez, F. G., \& Lent, R. (1992). Sources of mathematics self-efficacy in high school students. Career Development Quarterly, 41, 3-12. http://dx.doi.org/10.1002/j.2161-0045.1992.tb00350.x

Matsui, T., Matsui, K., \& Ohnishi, R. (1990). Mechanisms underlying math self-efficacy learning of college students. Journal of Vocational Behavior, 37, 225-238. http://dx.doi.org/10.1016/0001-8791(90)90042-Z

McArdle, J. J., \& Nesselroade, J. R. (2003). Growth curve analysis in contemporary psychological research. In J. A. Schinka \& W. F. Velicer (Eds.), Handbook of psychology: Research methods in psychology (pp. 447-480). New York: Wiley.

Meece, J. L., Blumenfeld, P. C., \& Hoyle, R. H. (1988). Students' goal orientations and cognitive engagement in

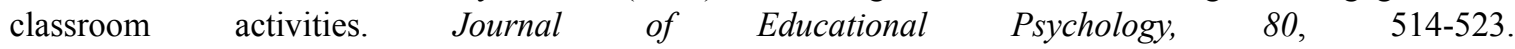
http://dx.doi.org/10.1037/0022-0663.80.4.514

Odgers, C. L., Moffitt, T. E., Tach, L. M., Sampson, R. J., Taylor, A., \& Matthews, C. L. (2009). The protective effects of neighborhood collective efficacy on British children growing up in deprivation: A developmental analysis. Developmental Psychology, 45(4), 942-957. http://dx.doi.org/10.1037/a0016162

Pajares, F. (1996a). Self-Efficacy beliefs and mathematical problem-solving of gifted students. Contemporary Educational Psychology, 21, 325-344. http://dx.doi.org/10.1006/ceps.1996.0025

Pajares, F. (1996b). Self-efficacy beliefs in academic settings. Review of Educational Research, 66(4), 543-578.

Pajares, F., \& Graham, L. (1999). Self-efficacy, motivation constructs, and mathematics performance of entering middle school students. Contemporary Educational Psychology, 24(124-139). http://dx.doi.org/10.1006/ceps.1998.0991

Pajares, F., Johnson, J., J, \& Usher, E. L. (2007). Sources of writing self-efficacy beliefs of elementary, middle, and high school students. Research in the Teaching of English, 42(1), 104-120.

Pajares, F., \& Kranzler, J. (1995). Self-efficacy beliefs and general mental ability in mathematical problem 
solving. Contemporary Educational Psychology, 20, 426-443. http://dx.doi.org/10.1006/ceps.1995.1029

Pajares, F., \& Miller, D. (1994). Role of self-efficacy and self-concept beliefs in mathematical problem solving: A path analysis. Journal of Educational Psychology, 86, 193-203. http://dx.doi.org/10.1037/0022-0663.86.2.193

Pajares, F., \& Valiante, C. (1999). Grade level and gender differences in the writing self-beliefs of middle school students. Contemporary Educational Psychology, 24, 390-405. http://dx.doi.org/10.1006/ceps.1998.0995

Phan, H. P. (2009a). Exploring students' reflective thinking practice, deep processing strategies, effort, and achievement goal orientations. Educational Psychology, 29(3), 297-313. http://dx.doi.org/10.1080/01443410902877988

Phan, H. P. (2009b). Relations between goals, self-efficacy, critical thinking and deep processing strategies: A path analysis. Educational Psychology, 29(7), 777-799. http://dx.doi.org/10.1080/01443410903289423

Phan, H. P. (2010a). Empirical model and analysis of mastery and performance-approach goals: A developmental approach. Educational Psychology, 30(5), 547-564. http://dx.doi.org/10.1080/01443410.2010.491936

Phan, H. P. (2010b). Students' academic performance and various cognitive processes of learning: An integrative framework and empirical analysis. Educational Psychology, 30(3), 297-322. http://dx.doi.org/10.1080/01443410903573297

Phan, H. P. (2011a). Cognitive processes in university learning: A developmental framework using structural equation modelling. British Journal of Educational Psychology, 81, 509-530. http://dx.doi.org/10.1348/2044-8279.002000

Phan, H. P. (2011b). Deep processing strategies and critical thinking: Developmental trajectories using latent growth analyses. The Journal of Educational Research, 104, 283-294. http://dx.doi.org/10.1080/00220671003739382

Phan, H. P. (2011c). Interrelations between self-efficacy and learning approaches: A developmental approach. Educational Psychology, 31(2), 225-246. http://dx.doi.org/10.1080/01443410.2010.545050

Phan, H. P. (2012). The development of English and mathematics self-efficacy: A latent growth curve analysis. The Journal of Educational Research, 105, 196 - 209. http://dx.doi.org/10.1080/00220671.2011.552132

Pintrich, P. R. (2000). Multiple-goals, multiple pathways: The role of goal orientation in learning and $\begin{array}{lllll}\text { achievement. Journal of Educational Psychology, } & \text { 92, }\end{array}$ http://dx.doi.org/10.1037/0022-0663.92.3.544

Pintrich, P. R., Conley, A. M., \& Kempler, T. M. (2003). Current issues in achievement goal theory and research. International Journal of Educational Research, 39, 319-337. http://dx.doi.org/10.1016/j.ijer.2004.06.002

Pintrich, P. R., Smith, D. A. F., Garcia, T., \& McKeachie, W. J. (1991). A manual for the use of the Motivated Strategies for Learning Questionnaire (MSLQ). Ann Arbor, MI: National Centre for Research to Improve Postsecondary Teaching and Learning.

Pintrich, P. R., Smith, D. A. F., Garcia, T., \& McKeachie, W. J. (1993). Reliability and predictive validity of the motivated strategies for learning questionnaire (MSLQ). Educational and Psychological Measurement, 53, 810-814. http://dx.doi.org/10.1177/0013164493053003024

Schumacker, R. E., \& Lomax, R. G. (2004). A beginner's guide to structural equation modeling (2nd ed.). Mahwah, NJ: Lawrence Erlbaum Associates, Inc.

Schunk, D. H. (1982). Effects of effort attributional feedback on children's perceived self-efficacy and $\begin{array}{lllll}\text { achievement. Journal of Educational Psychology, } & 74, & \text { 548-556. }\end{array}$ http://dx.doi.org/10.1037/0022-0663.74.4.548

Schunk, D. H. (1983). Ability versus effort attributional feedback: Differential effects on self-efficacy and $\begin{array}{lllll}\text { achievement. Journal of Educational Pychology, } & 75, & 848-856 .\end{array}$ http://dx.doi.org/10.1037/0022-0663.75.6.848

Schunk, D. H. (1984). Sequential attributional feedback and children's achievement behaviors. Journal of Educational Psychology, 76, 1159-1169. http://dx.doi.org/10.1037/0022-0663.76.6.1159

Schunk, D. H. (1987). Peer models and children's behavioral change. Review of Educational Research, 57, 149-174.

Schunk, D. H. (1991). Self-efficacy and academic motivation. Educational Psychologist, 26, 207-231. 
Schunk, D. H. (1995). Self-efficacy and education and instruction. In J. E. Maddux (Ed.), Self-efficacy, adaptation, and adjustment: Theory, research and application (pp. 283-301). New York: Plenum Press.

Schunk, D. H., \& Hanson, A. R. (1985). Peer models: Influence on children's self-efficacy and achievement. Journal of Educational Psychology, 77, 313-322. http://dx.doi.org/10.1037/0022-0663.77.3.313

Schunk, D. H., \& Hanson, A. R. (1989). Self-modeling and children's cognitive skill learning. Journal of Educational Psychology, 81, 155-163. http://dx.doi.org/10.1037/0022-0663.81.2.155

Schunk, D. H., Hanson, A. R., \& Cox, P. D. (1987). Peer-model attributes and children's achievement behaviors. Journal of Educational Psychology, 79, 54-61. http://dx.doi.org/10.1037/0022-0663.79.1.54

Senko, C., \& Miles, K. M. (2008). Pursuing their own learning agenda: How mastery-oriented students jeopardize their class performance. Contemporary Educational Psychology, 33, 561-583. http://dx.doi.org/10.1016/j.cedpsych.2007.12.001

Simons, J., Dewitte, S., \& Lens, W. (2004). The role of different types of instrumentality in motivation, study strategies, and performance: Know why you learn, so you'll know what you learn! British Journal of Educational Psychology, 74, 343-360. http://dx.doi.org/10.1348/0007099041552314

Sins, P. H. M., van Joolingen, W. R., Savelsbergh, E. R., \& van Hout-Wolters, B. (2008). Motivation and performance within a collaborative computer-based modeling task: Relations between students' achievement goal orientation, self-efficacy, cognitive processing, and achievement. Contemporary Educational Psychology, 33, 58-77. http://dx.doi.org/10.1016/j.cedpsych.2006.12.004

Skaalvik, E. M., \& Rankin, R. J. (1998). Self-concept, self-efficacy and achievement in mathematics: A test of causal relations. Paper presented at the Annual Meeting of the American Educational Research Association, San Diego, CA.

Smith, N., \& Miller, R. J. (2005). Learning approaches: Examination type, discipline of study, and gender. Educational Psychology, 25, 43-53. http://dx.doi.org/10.1080/0144341042000294886

Steiger, J. H. (1990). Structural model evaluation and modification: An interval estimation approach. Multivariate Behavioral Research, 25, 173-180. http://dx.doi.org/10.1207/s15327906mbr2502_4

Tanaka, A., \& Yamauchi, H. (2001). A model for achievement motives, goal orientations, intrinsic interest, and academic achievement. Psychological Reports, 88, 123-135. http://dx.doi.org/10.2466/pr0.2001.88.1.123

Urdan, T. (2004). Using multiple methods to assess students' perceptions of classroom goal structure. European Psychologist, 9(4), 222-231. http://dx.doi.org/10.1027/1016-9040.9.4.222

Urdan, T., Kneisel, L., \& Mason, V. (1999). Interpreting messages about motivation in the classrooms: Examining the effects of achievement goal structures. In T. Urdan (Ed.), Advances in motivation and achievement (Vol. 11). Stamford, CT: JAI.

Valle, A., Cabanach, R. G., Núñez, J. C., Gonnzález-Pienda, J., Rodríguez, S., \& Piñeiro, I. (2003). Multiple goals, motivation and academic learning British Journal of Educational Psychology, 73, 71-87. http://dx.doi.org/10.1348/000709903762869923

Vansteenkiste, M., Simons, J., Lens, W., Soenens, B., \& Matos, L. (2004). Less is something more: Goal-content matters. Journal of Educational Psychology, 96, 755-764. http://dx.doi.org/10.1037/0022-0663.96.4.755

Wigfield, A. (1994). Expectancy-value theory of achievement motivation: A developmental perspective. Educational Psychology Review, 6, 49-78. http://dx.doi.org/10.1007/BF02209024

Wigfield, A., \& Eccles, J. S. (2000). Expectancy-value theory of achievement motivation. Contemporary Educational Psychology, 25, 68-81. http://dx.doi.org/10.1006/ceps.1999.1015 